\title{
Super-hydrophobic magnesium oxychloride cement (MOC): from structural control to self-cleaning property evaluation
}

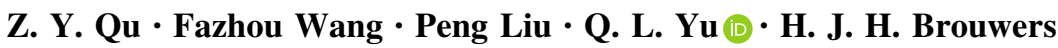

Received: 23 September 2019/Accepted: 17 February 2020/Published online: 6 March 2020

(C) The Author(s) 2020

\begin{abstract}
In this paper, magnesium oxychloride cement (MOC), which has a needle-like structure, is upgraded with super-hydrophobic surface using a facile method involving immersion in a FAS-ethanol solution. The influence of the molar ratios of the raw materials on the super-hydrophobic property was investigated. The phase compositions, microstructure, compressive strength, water resistance and wetting behaviour are studied in detail by X-Ray diffraction, scanning electron microscopy, a water contact angle measurement instrument, and mechanical testing. The water contact angle of as-prepared MOC reaches $152 \pm 1^{\circ}$ for the optimal mix design. The variation of the water contact angle of different mixes can be explained by the Cassie-Baxter model. The experiments using rolling off dust on the super hydrophobic
\end{abstract}

Z. Y. Qu · F. Wang ( $₫)$ · H. J. H. Brouwers State Key Laboratory of Silicate Materials for Architectures, Wuhan University of Technology, Wuhan 430070, People's Republic of China e-mail: fzhwang@whut.edu.cn

Z. Y. Qu · Q. L. Yu ( $₫)$ · H. J. H. Brouwers Department of the Built Environment, Eindhoven University of Technology, P.O. Box 513, 5600 MB Eindhoven, The Netherlands e-mail: q.yu@bwk.tue.nl

P. Liu

School of Chemistry, Chemical Engineering and Life Science, Wuhan University of Technology,

Wuhan 430070, People's Republic of China surface present excellent self-cleaning ability. Moreover, proposed super hydrophobic surface exhibited excellent UV-durability, indicating a promising potential for the outdoor application.

Keywords Magnesium oxychloride cement - Super hydrophobic $\cdot$ UV-durable $\cdot$ Water-resistance $\cdot$ Selfcleaning

\section{Introduction}

Magnesium oxychloride cement (MOC) has attracted extensive attention, as it is generally associated with ambient temperature curing and excellent materials properties such as fast setting, high mechanical strength, good resistance to abrasion and fire [1-5]. The behavior of MOC is mainly regulated by the composition and microstructure of the hydration products, produced through neutralization-hydrolysis-crystallization process in the ternary system of $\mathrm{MgO}-\mathrm{MgCl}_{2}-\mathrm{H}_{2} \mathrm{O}[1,6]$. At room temperature, the mechanism of formation of magnesium chloride hydrates in the $\mathrm{MgO}-\mathrm{MgCl}_{2}-\mathrm{H}_{2} \mathrm{O}$ system can be described by the following chemical reactions (Eqs. 1-3) [6, 7]: 


$$
\begin{aligned}
& 5 \mathrm{MgO}+\mathrm{MgCl}_{2}+13 \mathrm{H}_{2} \mathrm{O}=5 \mathrm{Mg}(\mathrm{OH})_{2} . \\
& \mathrm{MgCl}_{2} \cdot 8 \mathrm{H}_{2} \mathrm{O} \quad(\text { Phase } 5) \\
& 3 \mathrm{MgO}+\mathrm{MgCl}_{2}+11 \mathrm{H}_{2} \mathrm{O}=3 \mathrm{Mg}(\mathrm{OH})_{2} . \\
& \mathrm{MgCl}_{2} \cdot 8 \mathrm{H}_{2} \mathrm{O} \quad(\text { Phase } 3) \\
& \mathrm{MgO}+\mathrm{H}_{2} \mathrm{O}=\mathrm{Mg}(\mathrm{OH})_{2}
\end{aligned}
$$

Changing the proportion of $\mathrm{MgO}, \mathrm{MgCl}_{2}$ and $\mathrm{H}_{2} \mathrm{O}$ in this reaction system, such as molar ratios of $\mathrm{MgO}$ / $\mathrm{MgCl}_{2}$ and $\mathrm{H}_{2} \mathrm{O} / \mathrm{MgCl}_{2}$, can lead to significant differences concerning chemical compositions and consequently different materials performance of MOC [2]. Specifically, Phase 5 (P5) has been commonly recognized as the most desirable reaction product in MOC-based composites, as it is believed that the Phase 5 crystals can provide the best mechanical properties [2, 3, 6]. Generally, a molar ratio of over five for $\mathrm{MgO} / \mathrm{MgCl}_{2}$ is often used for manufacturing the MOC-based product [2, 6]. As a consequence, the hydration products usually consist of more P5 and some $\mathrm{Mg}(\mathrm{OH})_{2}$.

However, when exposed to water, Phase 5 will be easily decomposed to $\mathrm{Mg}(\mathrm{OH})_{2}$ that leads to a poor water resistance, which seriously restricts its outdoor applications. An efficient and facile way to improve the water resistance of MOC is through controlling the molar ratios of $\mathrm{MgO} / \mathrm{MgCl}_{2}$ and $\mathrm{H}_{2} \mathrm{O} / \mathrm{MgCl}_{2}$. Li et al. [2] investigated the influence of the molar ratios of raw materials on the properties of magnesium oxychloride cement. They found that there are three different structures of Phase 5 specified as plate-like, needlelike and gel-like crystals. Among them, needle like structure shows a better performance in terms of mechanical properties. However, as the packing of the needle-like structures resulting in more space for the water to penetrate, MOC rich in need-like Phase 5 always results in a poor water resistance and leads to a very low strength of $\mathrm{MOC}$ at ambient temperature after 28 days in water [8]. Another efficient method is to apply additives to improve the water resistance of MOC. $\mathrm{Li}$ and $\mathrm{Yu}$ [9] found that after the addition of active $\mathrm{SiO}_{2}$, the water resistance of MOC was increased, owing to the generation of new hydration products (S-1 gel) that lead to a denser matrix. Deng et al. [8] discovered that the addition of phosphate could increase the softening coefficient of 14 days' cured samples to above 0.8 after immersed in water for
15 days as more gel-like P5 is formed which increases the tortuosity of the MOC.

Preventing the water penetration by generating super-hydrophobic surfaces has already led to various new hybrid materials with astonishing properties [10-12]. A surface can be described as super hydrophobic if the contact angle (CA) of water on this surface is larger than $150^{\circ}[13,14]$. The best known example of super hydrophobic surface is the lotus leaf, on which water easily rolls off, leaving little or no residue and carrying away surface contamination, therefore showing excellent self-cleaning properties $[10,15]$. With the help of scanning electron microscopy (SEM), the mechanism behind this phenomenon has been resolved. The electron microscopy of the surface of lotus leaves shows protruding nubs of 20-40 $\mu \mathrm{m}$ apart each covered with a smaller scale rough of epicuticular wax crystalloids [12]. This wax only consists of $-\mathrm{C}-\mathrm{H}$ and $-\mathrm{C}-\mathrm{O}$ groups, which give the origin to the super hydrophobicity and selfcleaning properties of the lotus leaf. Since Tsujii et al. first fabricated biomimetic surfaces in the mid1990s, numerous smart and efficient methods for attaining rough surfaces to prepare super hydrophobic surface have been reported [12]. In summary [16], there are two main kinds of surface microstructures to prepare super hydrophobic surface: one is the hierarchical micro- and nanostructure like the lotus leaf and the other one is the unitary micro-line structure like the ramee leaf.

Considering the complexity of the preparation of micro-, nano-, and lotus-type micro-/nanocomposite structures, unitary micro-line structure provides a facile solution to prepare super hydrophobic surfaces $[16,17]$. Ogawa et al. prepared super hydrophobic film-coated nano-fibrous membranes based on the inspiration of self-cleaning silver ragwort leaves. After the modification with fluoroalkylsilane (FAS), the surface of the nano-fibrous membrane presented super hydrophobicity with the highest water contact angle of $162^{\circ}$ and the lowest water-roll angle of $2^{\circ}$ [18]. Li et al. reported a simple solution-immersion method to fabricate a super hydrophobic surface on a cellulose-based material (i.e. cotton fabric or paper). The surface morphology of the fabric provided ideal roughness for trapping the air to build a super hydrophobic surface [19]. Jiang et al. [20] prepared $\mathrm{Cu}(\mathrm{OH})_{2}$ nano-needle arrays presenting little contactangle hysteresis, even under certain hydrostatic 
pressures, by a facile chemical-base deposition method. The average length of the needles was $5 \mu \mathrm{m}$ and the average diameter of the nano-needle is $300 \mathrm{~nm}$. However, due to the restriction of the microstructure of the cement-based materials, fabrication of super hydrophobic surface with cementbased materials is still limited..

The present study aims to propose a novel method for the fabrication of super hydrophobic surface on MOC by applying the unique needle-like structure Phase 5 of MOC. The procedure is fairly facile to carry out and no special technique or equipment is required, so it is very cost-effective. The compressive strength and water resistance of the MOC samples were studied. The phase composition and microstructural properties are determined by using X-ray diffraction (XRD) and scanning electron microscopy (SEM). The water-repellency ability was evaluated by performing the water contact angle and water sliding angle tests using a Dataphysics OCA20 contact-angle system. As UV-durability property, which is crucial for practical outdoor use, mainly depends on the surface chemical composition and surface structures. As such UVdurability of the as prepared surface is also examined. The results show that the designed super MOC surface possesses a super hydrophobic property, together with an excellent water-repellency and self-cleaning ability.

\section{Experiment}

\subsection{Materials}

The starting raw materials for preparing the MOC cement paste included light-burnt magnesia powder $(\mathrm{MgO})$, magnesium chloride hexahydrate $\left(\mathrm{MgCl}_{2}\right.$ $6 \mathrm{H}_{2} \mathrm{O}$ ), and tap water. Both the $\mathrm{MgO}$ and $\mathrm{MgCl}_{2} \cdot 6 \mathrm{H}_{2} \mathrm{O}$ were provided by Sinopharm Chemical Reagent, China. Triethoxy-1H,1H,2H,2H-tridecafluoro-noctylsilane (FAS) and Ethanol was used to prepare a FAS-ethanol solution.

\subsection{Preparation of the super hydrophobic MOC samples}

The magnesium chloride hexahydrate was dissolved in water before use. The MOC samples were prepared by mixing $\mathrm{MgO}$ and the $\mathrm{MgCl}_{2} \cdot 6 \mathrm{H}_{2} \mathrm{O}$ solution. To find out an appropriate formulation of the MOC to provide sufficient surface roughness, MOC cement pastes using $\mathrm{MgO}$ and $\mathrm{MgCl}_{2} \cdot 6 \mathrm{H}_{2} \mathrm{O}$ with different molar ratios were designed, as shown in Table 1 . The paste is cast into the steel moulds applying a normal cement paste mixing step following EN 196-1 [21]. Based on the mixed recipe, the samples are designated as MOC510, MOC-68 and MOC-610. To prepare hydrophobic MOC samples, after 48 h' curing in the air, MOC products were placed in the FAS ethanol 5\% solution at room temperature for $24 \mathrm{~h}$. Subsequently they were dried at room temperature for $1 \mathrm{~h}$.

\subsection{Testing methods}

\subsubsection{Characterization}

The XRD analysis was performed by using a Bruker D8 advance powder X-ray diffractometer with a $\mathrm{Cu}$ tube $(20 \mathrm{kV}, 10 \mathrm{~mA})$ with a scanning range from $5^{\circ}$ to $65^{\circ}(2 \theta)$, applying a step $0.02^{\circ}$ and 0.2 s/step measuring time. The powder sample was prepared by crushing and grinding the solid MOC cement paste with a ball milling equipment, and then passing it through a sieve with a screen aperture of $75 \mu \mathrm{m}$. A contact angle meter DataPhysics SCA20 (DataPhysics Germany) was used to measure the static water contact angle and sliding angle with $10 \mu \mathrm{l}$ water drop at the ambient temperature. The morphologies of the MOC were observed using a field emission scanning electron microscopy (FESEM) of Quanta 450 (FEI USA) with the operation voltage of $5 \mathrm{kV}$ and spot size was set to 5.0.

\subsubsection{Self-cleaning behavior evaluation}

The wetting behavior of the samples was assessed in a simple qualitative manner by placing droplets of water

Table 1 Mixture recipe of the MOCs

\begin{tabular}{llc}
\hline Mixtures & \multicolumn{2}{l}{ Molar ratios } \\
\cline { 2 - 3 } & $\mathrm{MgO} / \mathrm{MgCl}_{2}$ & $\mathrm{H}_{2} \mathrm{O} / \mathrm{MgCl}_{2}{ }^{*}$ \\
\hline MOC-510 & 5 & 10 \\
MOC-68 & 6 & 8 \\
MOC-610 & 6 & 10 \\
\hline
\end{tabular}

*The crystal water of $\mathrm{MgCl}_{2} \cdot 6 \mathrm{H}_{2} \mathrm{O}$ is included 
on the surface of the plate samples and visually observing their movement. $50 \mathrm{~g}$ bottom ash were placed loosely on the super-hydrophobic MOC sample (the same recipe as MOC-610) for the test of selfcleaning ability. Water drops from a watering can were placed on the super hydrophobic MOC surface to clean the bottom ash.

\subsubsection{UV durability evaluation}

The UV durability test under different environmental conditions was performed in a set-up as shown in Fig. 1. In the present work, the experimental setup is composed of a light source, transport gas (air) supply, flow rate valves, relative humidity meter valve, and parameter measurement apparatus like temperature and relative humidity. The applied light source consists of three ultraviolet lamps of $25 \mathrm{~W}$ each, emitting an ultraviolet radiation (UVA) in the range of $300-400 \mathrm{~nm}$. The irradiance can be adjusted by a light intensity controller. The light intensity is measured with UVA radiometer. The light intensity $\mathrm{E}$ is kept constant at $14 \mathrm{~W} / \mathrm{m}^{2}$ to simulate outdoor conditions. The summary of the test conditions is shown in Table 2.

\section{Results and discussion}

\subsection{Crystalline composition}

The XRD patterns of the MOCs are presented in Fig. 2. It should be noted that for all the MOC

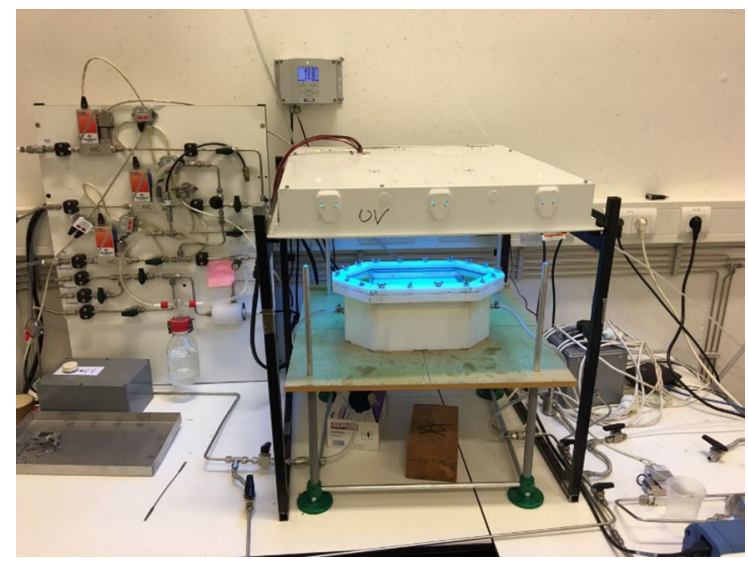

Fig. 1 Image of the UV durability test set-up
Table 2 Summary of the UV durability test conditions

\begin{tabular}{llll}
\hline Operating conditions & Test 1 & Test 2 & Test 3 \\
\hline Flow rate $(\mathrm{L} / \mathrm{min})$ & 5 & 5 & 5 \\
Temperature $\left({ }^{\circ} \mathrm{C}\right)$ & 20 & 50 & 50 \\
Relative humidity $(\%)$ & 50 & 50 & 70 \\
Radiation surface $\left(\mathrm{cm}^{2}\right)$ & 200 & 200 & 200 \\
Irradiance $\left(\mathrm{W} / \mathrm{m}^{2}\right)$ & 14 & 14 & 14 \\
\hline
\end{tabular}

specimens, the mineralogical phases consist of major Phase 5, minor $\mathrm{Mg}(\mathrm{OH})_{2}$ and unreacted $\mathrm{MgO}$ and $\mathrm{MgCO}_{3}$. This is in agreement with the previous studies $[2,4,6]$. As the Phase 5 is the most favourable crystalline phase $[2,6]$, the molar ratio of $\mathrm{MgO} / \mathrm{MgCl}_{2}$ is desired to be higher than 5 and the molar ratio of $\mathrm{H}_{2} \mathrm{O} / \mathrm{MgCl}_{2}$ is in the range of 6-15.

However, comparing the XRD patterns shown in Fig. 2, it can be found that MOC-510 exhibits the weakest characteristic peaks of unreacted $\mathrm{MgO}$ in the paste matrices as less $\mathrm{MgO}$ are used in this mixture. Both the MOC-68 and MOC-610 present stronger characteristic peaks of unreacted $\mathrm{MgO}$ because of the increase of the molar ratio of $\mathrm{MgO} / \mathrm{MgCl}_{2}$. The compounds of hydration product of the MOC samples are in good accordance with the phase diagram of $\mathrm{MgO}-\mathrm{MgCl}_{2}-\mathrm{H}_{2} \mathrm{O}$ system [7] and the previous research [6].

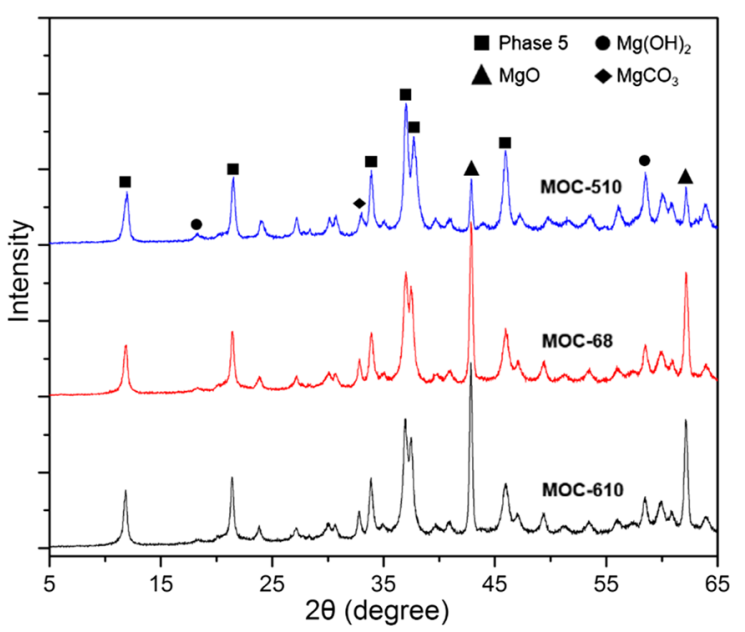

Fig. 2 XRD patterns of the MOCs at 28 days 


\subsection{Microstructure}

Figure 3 shows the SEM micrographs of the MOC samples. It is clear that all the samples present a composite structure consisting of needle-like Phase 5 and gel-like Phase 5. Figure 3a shows the micrographs of the MOC-510, which demonstrates that the MOC surface has an uneven structure. The morphology consists of gel-like Phase 5 and needle-like P5 crystal structures. Because of the differences between the recipes of the raw materials, the proportions of the Phase 5 with different structures are different in these three mixes. It can be seen that MOC-510 presents more gel-like Phase 5 as compared to the other two samples. This can be attributed to the smaller amount of $\mathrm{MgO}$ in the reaction system. As stated in [2, 6], $\mathrm{MgO}$ particles could act as a role of reaction seeds, which in turn increase the reaction sites in the MOC hydrated process. So less $\mathrm{MgO}$ seeds would increase the possibility of group growth of the MOC, which leads to more gel-like Phase 5. It can be observed that MOC-610 exhibits more needle-like Phase 5 than MOC-68 as shown in Fig. 3b, c, which is attributed to the higher amount of the free water in MOC-610. It has been reported in $[2,6,22]$ that the free water will react with the $\mathrm{MgO}$ during the hardening process. Hence, the more water the system contains, the more interspaces would be produced in the matrix after hardening of the MOC is completed.

\subsection{Compressive strength}

The compressive strengths of different mixtures after air curing for 3 days, 7 days and 14 days were
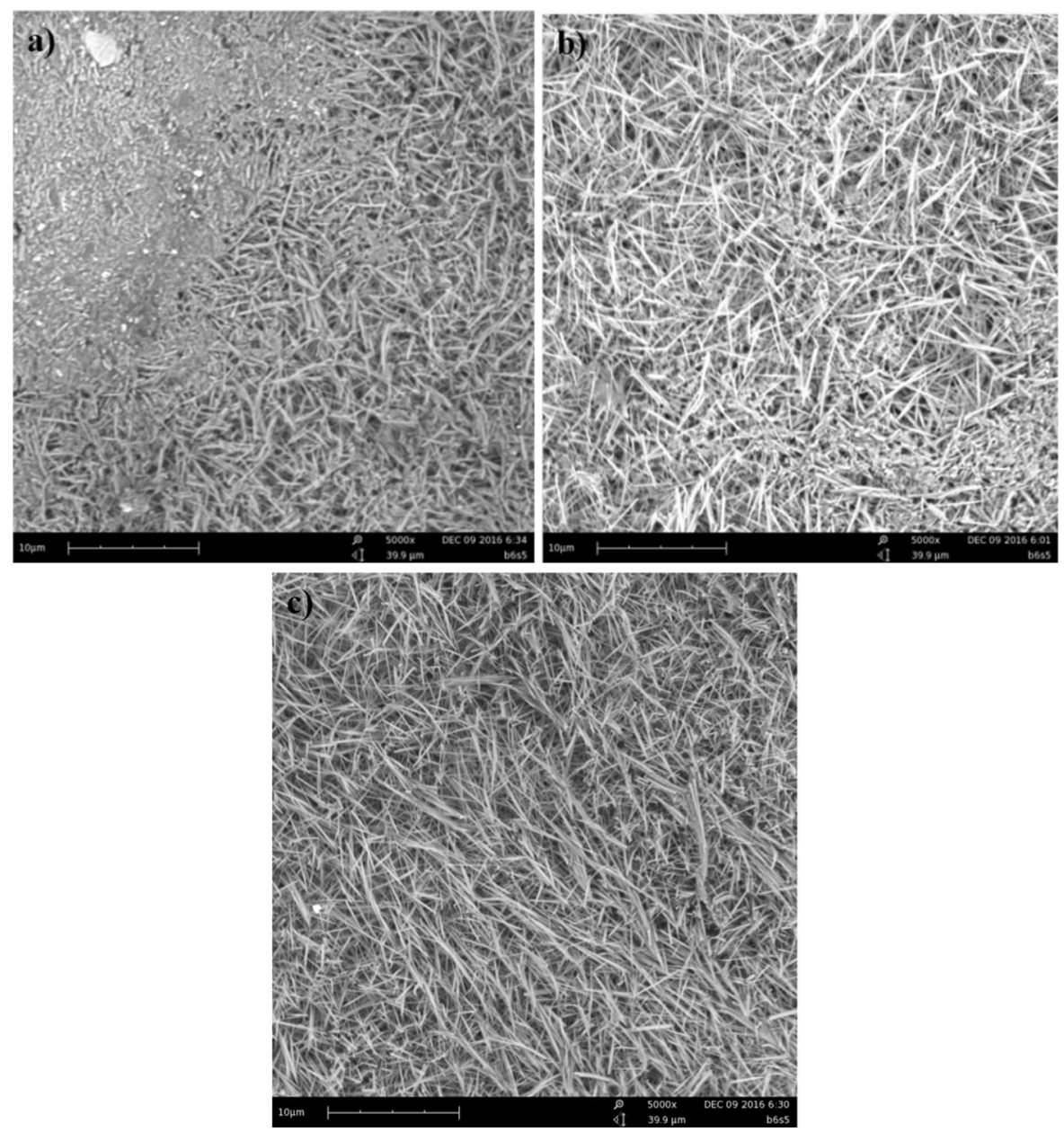

Fig. 3 SEM images of paste matrices of: a MOC-510, b MOC-68, c MOC-610 
determined, as shown in Fig. 4. Furthermore, the compressive strength changes after the immersion in water for $48 \mathrm{~h}$ are compared and shown in Fig. 5. It can be seen that with the increase of the curing time, the compressive strength of the all the samples increases. The 3 days compressive strength data of MOC-510, MOC-610 and MOC-68 were recorded to be $44.3 \mathrm{MPa}, 51.2 \mathrm{MPa}$ and $54.3 \mathrm{MPa}$, respectively. The 14 days compressive strength data were recorded to be $68.5 \mathrm{MPa}, 75.5 \mathrm{MPa}$ and $76.2 \mathrm{MPa}$ which presented an increase of $55 \%, 47 \%$ and $40 \%$, respectively, as compared to 3-day compressive strength values.

The continuous increase of the mechanical strength was attributed to the progressing hydration of MOC $[2,6]$. It should be noted that MOC-510 shown the weakest mechanical property. This can be attributed to the higher free water amount in its reaction system. As reported by $[2,23]$, the strength of MOC increases with the decrease of molar ratio of $\mathrm{H}_{2} \mathrm{O} / \mathrm{MgCl}_{2}$ with a fixed molar ratio of $\mathrm{MgO} / \mathrm{MgCl}_{2}$, while a higher molar ratio of $\mathrm{MgO} / \mathrm{MgCl}_{2}$ results in a higher strength with a fixed molar ratio of $\mathrm{H}_{2} \mathrm{O} / \mathrm{MgCl}_{2}$. However, it should be noticed that the compressive strength of MOC-610 is almost the same as MOC-68 whose molar ratio of $\mathrm{H}_{2} \mathrm{O} / \mathrm{MgCl}_{2}$ is lower. This is because the mechanical performance of $\mathrm{MOC}$ is highly related to the microstructure of the hydration product in MOC. It can be seen from the SEM images of Fig. 3, the formed needle crystals of MOC-610 are long and thin and highly intergrown. Li [24] has reported that this

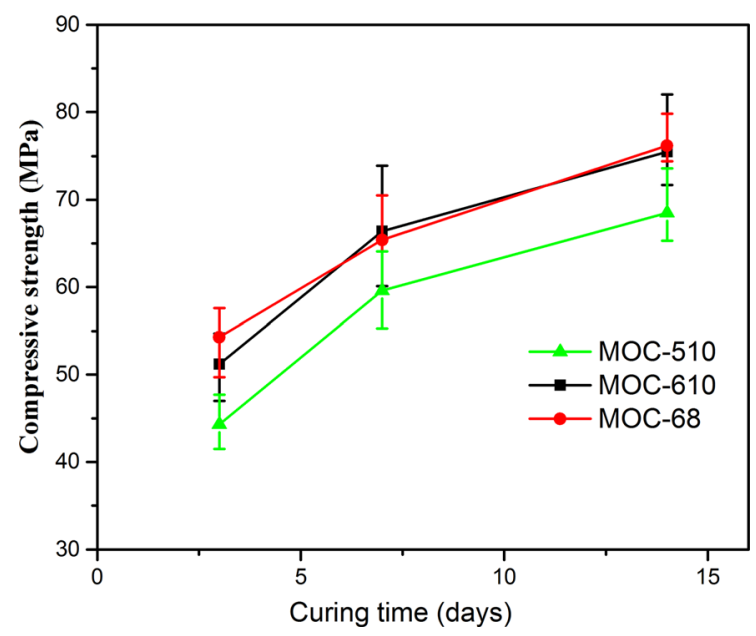

Fig. 4 Compressive strength development of different MOC mixes unique structure is beneficial to disperse the strength and lead to superior mechanical strengths.

The water resistance improvement of MOC pastes after super hydrophobic modification was performed can be seen from the compressive strength changes after soaking samples for $48 \mathrm{~h}$, as shown in Fig. 5a, b. It can be seen that the super hydrophobic modification significantly improves the water resistance of MOC. Without the modification, the compressive strengths of MOC-68, MOC-610 and MOC-510 is only 9.3 MPa and $9 \mathrm{MPa}$ and $9.5 \mathrm{MPa}$, respectively after soaking for $48 \mathrm{~h}$. The compressive strength retentions of the MOC-68, MOC-610 and MOC-510 are only $17.1 \%$, $17.6 \%$ and $21.4 \%$, respectively. This is due to the decomposition of the hydration products into $\mathrm{Mg}(\mathrm{OH})_{2}$ in water, as reported by [6, 25]. It should be noted that the compressive strength retention of MOC-510 is higher than the other two samples. This is due to more gel-like Phase 5 in MOC-510, which has been reported to efficiently improve the water resistance of MOC [2]. Owing to the super hydrophobic treatment, all of the MOC samples have a much higher compressive strength retention than unmodified samples. The compressive strength retentions of MOC-68, MOC-610 and MOC-510 after soaking $48 \mathrm{~h}$ were $91.3 \%, 99 \%$ and $91.2 \%$, respectively, indicating the hydrophobic treatment is highly effective in terms of improving water resistance of MOC.

\subsection{Hydrophobic performance}

The water contact angle (CA) was used to evaluate the surface wettability of the designed MOC mixtures and the measured CAs are shown in Fig. 6. It can be seen that contact angles measured on the surfaces of different MOC pastes are different. As shown in Fig. 6a, the MOC-510 has a water contact angle about $130^{\circ}$, indicating a hydrophobic property $[12,13]$. After the increase of the $\mathrm{MgO}$ content, the CA of the MOC-610 increased to about $152^{\circ}$ as shown in Fig. 6c, indicating that the MOC surface becomes super hydrophobic. On the contrary, the water repellent capability of MOC-68 decreases and the CA decreases to about $143^{\circ}$ after lowering the amount of $\mathrm{MgO}$.

The change of the surface microstructures of different recipes (Fig. 3a-c) is believed to be responsible for the increase of CA. According to the ideal Young equation: 


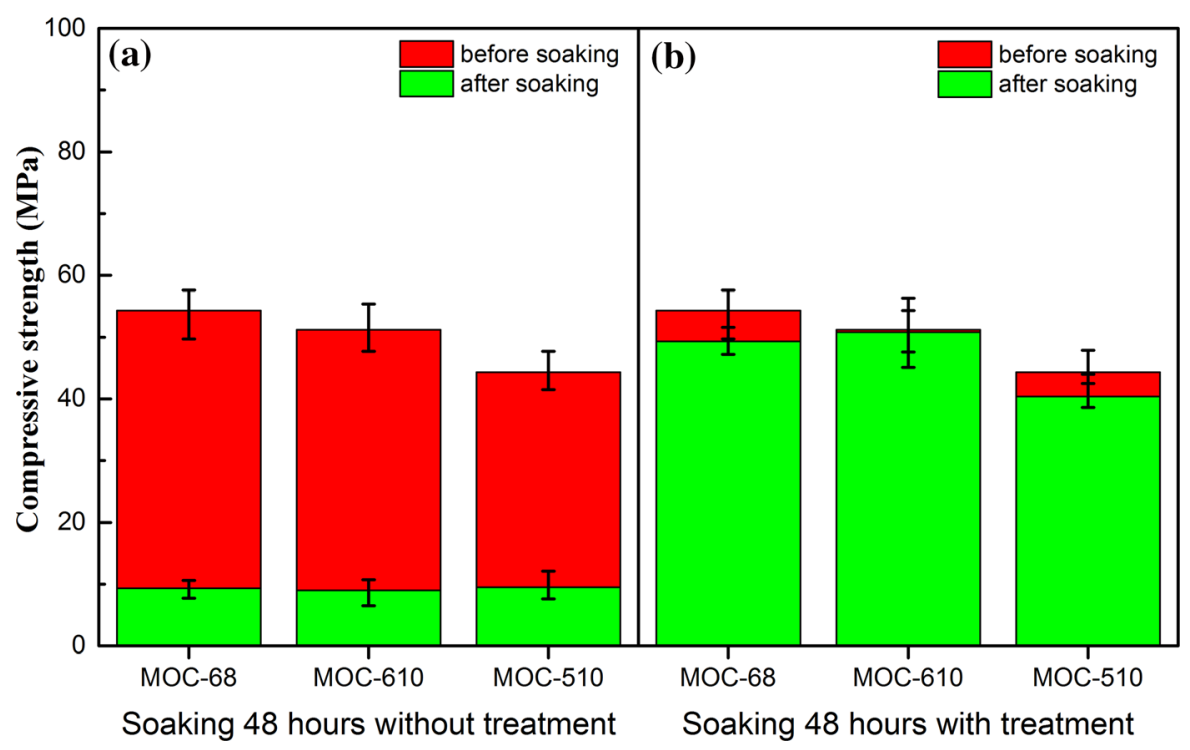

Fig. 5 Comparison between compressive strength of the MOCs before and after 48 h' soaking: a without FAS treatment and b with FAS treatment

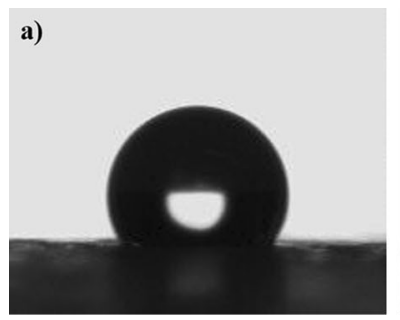

b)

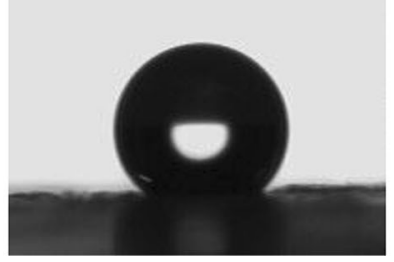

c)

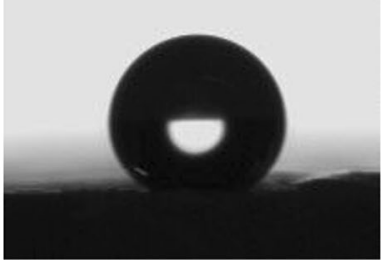

Fig. 6 Water contact angle of: a the MOC-510, $130^{\circ} \pm 1^{\circ}$, b the MOC-68, $143^{\circ} \pm 1^{\circ}$, c the MOC- $610,152 \pm 1^{\circ}$

$\cos \theta_{\mathrm{y}}=\frac{\gamma_{\mathrm{s}-\mathrm{g}}-\gamma_{1-\mathrm{s}}}{\gamma_{1-\mathrm{g}}}$

and the Cassie-Baxter equation:

$\cos \theta_{\mathrm{cb}}=r_{f} \cdot \cos \theta_{\mathrm{y}}+f-1$

where $\gamma_{1-\mathrm{g}}, \gamma_{\mathrm{s}-\mathrm{g}}$, and $\gamma_{1-\mathrm{s}}$ represent the liquid-gas, solidgas, and liquid-solid interfacial tensions, respectively, and $\theta_{\mathrm{y}}$ is the contact angle, $\theta_{\mathrm{cb}}$ is the apparent contact angle on the rough surface. Equation (5) describes the apparent contact angle in the heterogeneous regime $[26,27]$. The roughness ratio $\left(r_{f}\right)$ is defined as the ratio of the true area of the surface to its projection area. The variable $f$ is defined as the fraction of the project area of the surface that is wetted by water. For super hydrophobic MOC, air bubbles are enclosed in the pores among the hierarchical crosslinking need-like Phase 5 structures. Without the surface modification, water can easily spread on MOC as the P5 is very hydrophilic. Hence, the value of $r_{1-s}$ is very small in ideal Young equation. The value of $\theta_{\mathrm{y}}$ ranges from 0 to $90^{\circ}$ and the value of $\cos \theta_{y}$ ranges from 0 to 1 . In the Cassie-Baxter equation, both $r_{f}$ and $f$ range from 0 to 1 $[12,26]$. The rougher the surface is, the smaller the values of $r_{f}$ and $f$ are [26]. As a result, on a rough surface, the value of $\cos \theta_{\mathrm{cb}}$ vary between -1 and 0 and the value of $\theta_{\mathrm{cb}}$ between $90^{\circ}$ and $180^{\circ}$. Hence, a rougher surface will lead to a larger contact angle and more hydrophobic behaviour. When gel-like Phase 5 is generated among the needle-like structure, it will fill in the interspace that in turn decreases the air amount for air trapping. This can be used to explain the decrease of super hydrophobic ability from MOC-610 to MOC-510 as the amount gel-like Phase 5 increases.

Nano-needle structures have been reported beneficial to fabricate the super hydrophobic surface [20]. Such a unique structure offers two advantages: (1) 
needle structures are likely to minimize the contact area between the solid and liquid interface, and their remarkable length prevents contact area between the MOC surface and water, (2) the crosslinking structure can effectively trap air and vigorously support the enwrapped liquid-air interface. It is concluded that MOC products with needle-like Phase 5 are ideal raw materials to fabricate super hydrophobic surfaces. Furthermore, it has been reported that needle-like Phase 5 presents a better mechanical performance than gel-like or plate-like Phase $5[2,6]$. This design thus favours both super hydrophobicity and the mechanical strength of MOC products.

\subsection{Self-cleaning and UV-resistance ability}

Barthlott et al. reported that water droplets can roll off from the lotus leaves and remove the dust particles $[14,28,29]$. As MOC products are often used for a decorative purpose (e.g. decoration boards), it will be very meaningful for MOC possessing the self-cleaning ability. Figure 7a shows the results of rolling water on the super hydrophobic MOC surface (MOC-610).

UV-resistivity which is crucial for practical outdoor applications, mainly depends on the surface chemical composition and surface structures [30-33]. According to $[34,35]$, low-energy coating modification with a long chain organic molecule, such as FAS, is one possible solution to achieve the goal of fabricating UV-durable super hydrophobic surface. In order to assess the UV-durability of the as-prepared super

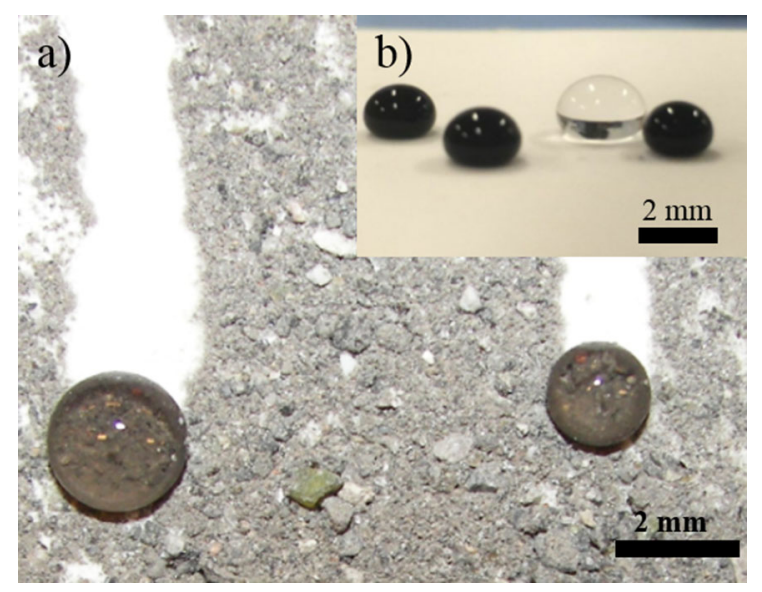

Fig. 7 Assessment of the hydrophobicity and self-cleaning ability by: a the rolling of particles, and $\mathbf{b}$ blue ink and water drops on the super hydrophobic surface hydrophobic surface, the samples were exposed to UV light for the period of 7 days at different temperatures and humidity levels, and the wetting behaviours were measured every $30 \mathrm{~min}$. The static contact angle and sliding angle as a function of UV-irradiation time are presented in Fig. 8. It is shown that after 7 days' UV irradiation, the surface still exhibits a contact angle of $152.1^{\circ}$ and a sliding angle of $8^{\circ}$ at $25^{\circ} \mathrm{C}$ and $50 \%$ humidity and a contact angle of $152.8^{\circ}$ and a sliding angle of $9^{\circ}$ at higher temperature. Even under a higher humidity, the MOC surface presents a contact angle of $152.3^{\circ}$ and a sliding angle of $8^{\circ}$, suggesting a superior UV-durability.

The results here confirm that the as-prepared MOC super hydrophobic surface is very stable under strong UV irradiation. This can be attributed to both the properties of the MOC and the low surface energy of FAS. It has been widely reported that MOC possesses high strength and stability used in dry conditions $[2,6]$. The rough needle-like structure of the MOC matrix is therefore stable. Secondly, FAS, which has been applied on different kinds of substrate such as metal, ceramic and polymers to fabricate UV-durable super hydrophobic surface [11], is very stable. This can be attributed to the long chain of the FAS coated on the surface, which can provide a large amount of C-F bonds. It should be noted that the applied chemicals as well as the modification methods are rather economically effective and simple, which make the large scale industrial production relatively

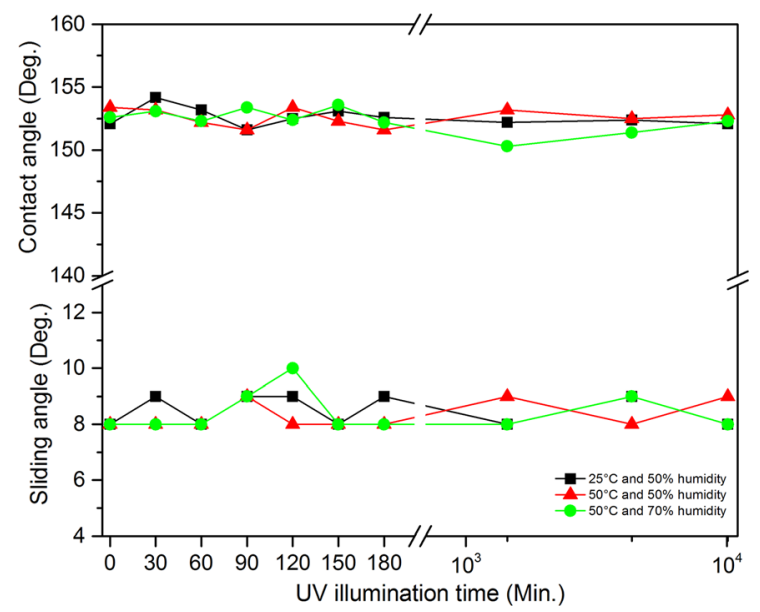

Fig. 8 Contact angle and sliding angle of MOC-68 samples as a function of UV-irradiation $\left(E=14 \mathrm{~W} / \mathrm{m}^{2}\right)$ time under different environmental conditions 
feasible. The bond energy is $485 \mathrm{~kJ} / \mathrm{mol}$ that cannot be broken by the UV light ranging from 314 to $419 \mathrm{~kJ} / \mathrm{mol}$ [30]. Hence, it is necessary to apply low surface energy chemicals with long C-F chain to prepare UV durable super hydrophobic surface with cement-based materials.

\section{Conclusions}

A super hydrophobic MOC surface with excellent selfcleaning ability was fabricated applying a facile solution immersion method with FAS. The influences of the molar ratio on the microstructure, compressive strength, water resistance and hydrophobic performance were investigated. The self-cleaning ability and UV-durability were characterized. Based the presented results, the following conclusions can be reached:

1. Through the control of the $\mathrm{MgO} / \mathrm{MgCl}_{2}$ and $\mathrm{H}_{2} \mathrm{O}$ / $\mathrm{MgCl}_{2}$ molar ratios, MOC samples with different microstructures were acquired. From the XRD and SEM results, it can be concluded that MOC with $\mathrm{MgO} / \mathrm{MgCl}_{2}$ ration of 5 exhibits a higher amount of gel-like Phase 5 and $\mathrm{MOC}$ with $\mathrm{MgO} / \mathrm{MgCl}_{2}$ presents a higher amount of nano-needle like Phase 5.

2. The compressive strength of $\mathrm{MOC}$ with $\mathrm{MgO} /$ $\mathrm{MgCl}_{2}$ ratio of 6 at 14 days reach about $75 \mathrm{MPa}$, indicating a great potential for structural application.

3. The hydrophobic treatment improves the water resistance of the MOC samples. The compressive strength retentions after 48 h' water soaking of reference samples were only $17.1 \%, 17.6 \%$ and $21.4 \%$, respectively, before the modification by FAS. However, the compressive strength retentions increased to $91.3 \%, 99 \%$ and $91.2 \%$, respectively, after the hydrophobic treatment.

4. Owing to the large amount of nano-needle like Phase 5 structures, MOC with the $\mathrm{MgO}: \mathrm{MgCl}_{2}$ : $\mathrm{H}_{2} \mathrm{O}$ ratio of $6: 1: 10$ is found to be the optimum recipe for the super hydrophobic surface fabrication, having a water contact angle of $152^{\circ} \pm 1^{\circ}$.

5. The prepared super hydrophobic surface presents an excellent self-cleaning ability. Moreover, the super hydrophobic MOC surface was found to be highly durable under UV irradiation.
Acknowledgements The authors would like to acknowledge the financial support by STW-foundation (10979) and the EPSRC-NSFC Joint Research Project (No. 51461135005) for funding this research. Mrs. A.C.A. Delsing in the lab of Building Physics and Services at Eindhoven University of Technology is acknowledged for providing experimental support on the SEM analysis. Furthermore, the authors wish to express their gratitude to the following sponsors of the Building Materials research group at TU Eindhoven: Rijkswaterstaat Grote Projecten en Onderhoud; Graniet-Import Benelux; Kijlstra Betonmortel; Struyk Verwo; Attero; Enci; Rijkswaterstaat Zee en Delta-District Noord; Van Gansewinkel Minerals; BTE; V.d. Bosch Beton; Selor; GMB; Icopal; BN International; Eltomation;Knuaf Gips; Hess AAC Systems; Kronos; Joma; CRH Europe Sustainable Concrete Centre; Cement \& Beton Centrum; Heros; Inashco; Keim; Sirius International; Boskalis; NNERGY; Millvision; Sappi and Studio Roex (in chronological order of joining).

Funding This study was funded by STW-foundation (10979) and the EPSRC-NSFC Joint Research Project (No. 51461135005).

\section{Compliance with ethical standards}

Conflict of interest The authors declare that they have no conflict of interest.

Open Access This article is licensed under a Creative Commons Attribution 4.0 International License, which permits use, sharing, adaptation, distribution and reproduction in any medium or format, as long as you give appropriate credit to the original author(s) and the source, provide a link to the Creative Commons licence, and indicate if changes were made. The images or other third party material in this article are included in the article's Creative Commons licence, unless indicated otherwise in a credit line to the material. If material is not included in the article's Creative Commons licence and your intended use is not permitted by statutory regulation or exceeds the permitted use, you will need to obtain permission directly from the copyright holder. To view a copy of this licence, visit http://creativecommons.org/licenses/by/4.0/.

\section{References}

1. Dehua D, Chuanmei Z (1999) The formation mechanism of the hydrate phases in magnesium oxychloride cement. Cem Concr Res 29(9):1365-1371

2. Li Z, Chau CK (2007) Influence of molar ratios on properties of magnesium oxychloride cement. Cem Concr Res 37(6):866-870

3. Liu Z, Wang S, Huang J et al (2015) Experimental investigation on the properties and microstructure of magnesium oxychloride cement prepared with caustic magnesite and dolomite. Constr Build Mater 85:247-255

4. Liu Z, Balonis M, Huang J et al (2017) The influence of composition and temperature on hydrated phase 
assemblages in magnesium oxychloride cements. J Am Ceram Soc 100(7):3246-3261

5. Xu B, Ma H, Hu C et al (2016) Influence of curing regimes on mechanical properties of magnesium oxychloride cement-based composites. Constr Build Mater 102:613-619

6. Li Y, Li Z, Pei H et al (2016) The influence of FeSO 4 and KH 2 PO 4 on the performance of magnesium oxychloride cement. Constr Build Mater 102:233-238

7. Chau CK, Chan J, Li Z (2009) Influences of fly ash on magnesium oxychloride mortar. Cement Concr Compos 31(4):250-254

8. Deng DH (2003) The mechanism for soluble phosphates to improve the water resistance of magnesium oxychloride cement. Cem Concr Res 33(9):1311-1317

9. Li C, Yu H (2010) Influence of fly ash and silica fume on water-resistant property of magnesium oxychloride cement. J Wuhan Univ Technol Mater Sci Ed 25(4):721-724

10. Grumbein S, Minev D, Tallawi M et al (2016) Hydrophobic properties of biofilm-enriched hybrid mortar. Adv Mater 28(37):8138-8143

11. Levkin PA, Svec F, Fréchet JMJ (2009) Porous polymer coatings: a versatile approach to superhydrophobic surfaces. Adv Func Mater 19(12):1993-1998

12. Guo Z, Liu W, Su BL (2011) Superhydrophobic surfaces: from natural to biomimetic to functional. J Colloid Interface Sci 353(2):335-355

13. Jiang L, Zhao Y, Zhai J (2004) A lotus-leaf-like superhydrophobic surface: a porous microsphere/nanofiber composite film prepared by electrohydrodynamics. Angew Chem 116(33):4438-4441

14. Erbil HY, Demirel AL, Avc1 Y et al (2003) Transformation of a simple plastic into a superhydrophobic surface. Science 299(5611):1377-1380

15. Rao AV, Kulkarni MM, Bhagat SD (2005) Transport of liquids using superhydrophobic aerogels. J Colloid Interface Sci 285(1):413-418

16. Guo Z, Liu W (2007) Biomimic from the superhydrophobic plant leaves in nature: binary structure and unitary structure. Plant Sci 172(6):1103-1112

17. Ogawa T, Ding B, Sone Y et al (2007) Super-hydrophobic surfaces of layer-by-layer structured film-coated electrospun nanofibrous membranes. Nanotechnology 18(16): 165607

18. Feng L, Che Y, Liu Y et al (2013) Fabrication of superhydrophobic aluminium alloy surface with excellent corrosion resistance by a facile and environment-friendly method. Appl Surf Sci 283:367-374

19. Li S, Zhang S, Wang X (2008) Fabrication of superhydrophobic cellulose-based materials through a solutionimmersion process. Langmuir 24(10):5585-5590

20. Yao X, Chen Q, Xu L et al (2010) Bioinspired ribbed nanoneedles with robust superhydrophobicity. Adv Func Mater 20(4):656-662
21. EN T (2005) 196-1. Methods of testing cement-Part 1: determination of strength. European Committee for standardization, 26

22. Bilinski H, Matković B, Mažuranić C et al (1984) The formation of magnesium oxychloride phases in the systems $\mathrm{MgO}-\mathrm{MgCl} 2-\mathrm{H} 2 \mathrm{O}$ and $\mathrm{NaOH}-\mathrm{MgCl} 2-\mathrm{H} 2 \mathrm{O}$. J Am Ceram Soc 67(4):266-269

23. Dehua D, Chuanmei Z (1996) The effect of aluminate minerals on the phases in magnesium oxychloride cement. Cem Concr Res 26(8):1203-1211

24. Li Y, Yu H, Zheng L et al (2013) Compressive strength of fly ash magnesium oxychloride cement containing granite wastes. Constr Build Mater 38:1-7

25. Beaudoin JJ, Ramachandran VS (1975) Strength development in magnesium oxychloride and other cements. Cem Concr Res 5(6):617-630

26. Marmur A (2003) Wetting on hydrophobic rough surfaces: to be heterogeneous or not to be? Langmuir 19(20):8343-8348

27. Marmur A (2004) The lotus effect: superhydrophobicity and metastability. Langmuir 20(9):3517-3519

28. Neinhuis C, Barthlott W (1997) Characterization and distribution of water-repellent, self-cleaning plant surfaces. Ann Bot 79:667-677

29. Roach P, Shirtcliffe NJ, Newton MI (2008) Progess in superhydrophobic surface development. Soft Matter 4(2):224-240

30. Deng Y et al (2015) Mechanically robust superhydrophobic steel surface with anti-icing, UV-durability, and corrosion resistance properties. ACS Appl Mater Interfaces 7(11):6260-6272

31. Manca M, Cannavale A, De Marco L et al (2009) Durable superhydrophobic and antireflective surfaces by trimethylsilanized silica nanoparticles-based sol-gel processing. Langmuir 25(11):6357-6362

32. Verho T, Bower C, Andrew P et al (2011) Mechanically durable superhydrophobic surfaces. Adv Mater 23(5):673-678

33. Fürstner R, Barthlott W, Neinhuis C et al (2005) Wetting and self-cleaning properties of artificial superhydrophobic surfaces. Langmuir 21(3):956-961

34. Miwa M, Nakajima A, Fujishima A et al (2000) Effects of the surface roughness on sliding angles of water droplets on superhydrophobic surfaces. Langmuir 16(13):5754-5760

35. Boreyko JB, Chen CH (2009) Self-propelled dropwise condensate on superhydrophobic surfaces. Phys Rev Lett 103(18): 184501

Publisher's Note Springer Nature remains neutral with regard to jurisdictional claims in published maps and institutional affiliations. 